\title{
PENGEMBANGAN KEWIRAUSAHAAN “KREASI PEMPEK BERBAHAN NASI” SEBAGAI PRODUK MAKANAN KHAS KOTA PALEMBANG
}

\author{
Meilin Veronica'), Reny Aziatul Febriani'2), Rafika Sari ${ }^{3)}$ \\ 1)233)Fakultas Ekonomi, Universitas Indo Global Mandiri, Palembang \\ Jln. Jenderal Sudirman No. 629 Km 4, Palembang

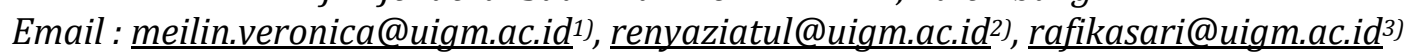

\begin{abstract}
ABSTRAK
Pengembangan Kewirausahaan "Kreasi Pempek Berbahan Nasi" Sebagai Produk Makanan Khas Kota Palembang bertujuan untuk memperkenalkan dan mempromosikan usaha pempek berbahan nasi ditempat target mitra sehingga menjadi makanan pengganti ikan agar dapat meningkatkan penghasilan warga sekitar. Metode Pelaksanaan Pengabdian terdiri atas 3 tahap antara lain persiapan Pelaksanaan PKM, Observasi Lokasi dan Pelatihan. Pelatihan terdiri atas Pelatihan pembuatan pempek nasi, Memberikan pelatihan pencatatan administrasi Produksi Dan Penjualan Pempek Nasi (Pembukuan), Pelatihan tentang pengenalan bentuk Packaging shape (bentuk kemasan);Pelatihan tentang pengenalan pemasaran secara online.

Hasil pelaksanaan kegiatan pengabdian kepada masyarakat ini adalah tindak lanjut hasil evaluasi, perluasan market penjualan dan inovasi produk. Beberapa saran yang dapat diterapkan adalah membuat kuesioner untuk mengukur tingkat keberhasil program pengabdian, menggunakan sosial media, memilih tempat strategis, menjalin hubungan baik dengan pelanggan dan mengembangkan jalur distribusi intensif
\end{abstract}

Kata kunci : Pempek berbahan nasi, brand image, kelompok usaha mandiri

\section{PENDAHULUAN}

Pempek atau empek-empek adalah makanan khas Palembang yang Pada awalnya pempek dibuat dari daging ikan belida. Namun, dengan semakin langka dan mahalnya harga ikan belida, ikan tersebut lalu diganti dengan ikan gabus yang harganya lebih murah, tetapi dengan rasa yang tetap gurih. Pada perkembangan selanjutnya, beberapa jenis ikan sungai lainnya juga dapat digunakan, misalnya ikan putak, toman, dan bujuk. Dipakai juga jenis ikan laut seperti tenggiri, kakap merah, parangparang, ekor kuning, dan ikan sebelah. Bahkan ada juga yang menggunakan ikan dencis, ikan lele serta ikan tuna putih.

Penyajian pempek ditemani oleh kuah saus berwarna hitam kecokelat-cokelatan, yang disebut cuka atau cuko (bahasa Palembang). Cuko dibuat dari air yang dididihkan, kemudian ditambah gula merah, ebi (udang kering), cabai rawit tumbuk, bawang putih, dan garam. Bagi masyarakat asli Palembang, cuko dari dulu dibuat pedas untuk menambah nafsu makan. Namun seiring masuknya pendatang dari luar Pulau Sumatera maka saat ini banyak ditemukan cuko dengan rasa manis bagi yang tidak menyukai pedas. Pelengkap yang lain untuk menyantap penganan khas ini adalah mentimun segar yang diiris dadu dan mie kuning.terbuat dari daging ikan yang digiling lembut dan tepung kanji (secara salah kaprah sering disebut sebagai "tepung sagu"), serta beberapa komposisi lain seperti telur, bawang putih yang dihaluskan, penyedap rasa dan garam.Pempek bisa ditemukan dengan sangat mudah di seantero Kota Palembang; ada yang menjual di restoran, ada yang di pinggir jalan, dan juga ada yang dipikul. Tahun 1980-an, penjual biasa memikul satu keranjang penuh pempek sambil berjalan kaki berkeliling menjajakan makanannya.

Saat ini Kota Palembang telah menjadi salah satu tujuan wisata bagi turis lokal maupun mancanegara. Daya tarik kota Palembang terletak pada tempat wisata, kuliner, pekan olahraga, acara kebudayaan dll. Berbagai upaya dilakukan pemerintah untuk meningkatkan jumlah pengunjung, mulai dari perbaikan infrastruktur, perbaikan objek wisata, menyelenggarakan pentas budaya dan promosi kuliner. Saat ini, wisata kuliner belum menunjukkan peningkatan yang signifikan (Suherlan \& Hidayah, 2015). Hal ini akan cepat terwujud jika masyarakat turut serta berinovasi dan mempromosikan kuliner lokal Sumatera Selatan. 
Kegiatan pengabdian kepada masyarakat yang diajukan ini, terdiri 2 (dua) target yang berbeda, yaitu (1) Meningkatkan brand image pempek berbahan nasi menjadi makanan khas kota Palembang (2) Meningkatkan perekonomian masyarakat ekonomi lemah dilingkungan mitra. Kedua target tersebut saling bersinergi, sehingga akan menjadi tujuan akhir dari kegiatan pengabdian ini.

Produk yang menjadi target pengembangan adalah Pempek berbahan nasi. Pempek merupakan salah satu makanan khas masyarakat Sumatera Selatan yang sampai saat ini banyak diminati. Pempek secara turun temurun telah diproduksi dengan cita rasa dan teknik pembuatan yang khas. Pempek dapat dijadikan sebagai makan ringan atau sebagai pengganti lauk pauk. Sampai saat ini pempek merupakan industri rumahan (home industry). Kuliner lokal merupakan cara terbaik untuk melihat warisan budaya tak benda sebuah destinasi adalah melalui konsumsi (Yurtseven \& Kaya, 2011). Pada dasarnya masyarakat Palembang merupakan masyarakat yang konsumtif terhadap kuliner lokal (anita, 2012), potensi wisata kuliner dapat mendukung pontensi pariwisata (Besra, 2012) sehingga dapat menunjang program visit to Palembang.

Target mitra adalah masyarakat ekonomi lemah yang tinggal di Jl. Pangeran Sidoing Kenayan RT.11 RW.04 Kelurahan Karang Anyar Kecamatan Gandus Sumatera Selatan. Terpilih menjadi target mitra karena letaknya tidak jauh dari kampus Universitas Indo Global Mandiri. Yang mewakili target mitra adalah ketua RT setempat.

Saat ini kebutuhan hidup semakin tinggi, pendapatan yang diterima tidak lagi mencukupi standar hidup. Bagi masyarakat yang memiliki pendapatan dibawah standar, tentu sangat berat menjalani kehidupan sehari-hari. Oleh karena itu peran dosen di Perguruan tinggi sangat dibutuhkan untuk membantu menyelesaikan masalah. Cara yang dilakukan adalah memberdayakan masyarakat yang tidak produktif secara ekonomi/sosial menjadi produktif, dengan memberikan soft dan hard skill kepada warga sebagai bekal membuka peluang usaha baru.

Adapun permasalah dari masing-masing target dijelaskan sebagai berikut :

1. Permasalahan mitra saat ini

Yang menjadi target mitra adalah masyarakat yang tinggal di Jl. Pangeran Sidoing Kenayan RT.11 RW.04 Kelurahan Karang Anyar Kecamatan Gandus Sumatera Selatan. Target mitra yang dimaksud adalah khusus bagi ibu rumah tangga yang tidak produktif.

Alasan menjadi target mitra, karena masyarakat yang dimaksud termasuk golongan masyarakat ekonomi lemah. Mereka memiliki pendapatan dibawah UMR (rendah). Mayoritas kepala keluarga berkerja sebagai pedagang/ buruh/ tukang parkir di pasar jaya Pal 5, yang letaknya \pm 500 meter dari tempat tinggal. Umumnya mereka adalah warga pendatang yang telah menetap bertahun-tahun dengan menyewa rumah di lokasi sekitar target mitra. Rata-rata memiliki tingkat pendidikan yang rendah, yaitu hanya sampai SD/SMP/SMA. Sulitnya mencari pekerjaan menyebabkan mereka tetap bertahan dengan pekerjaan tersebut. Berikut kondisi pemukiman disekitar tempat target mitra :

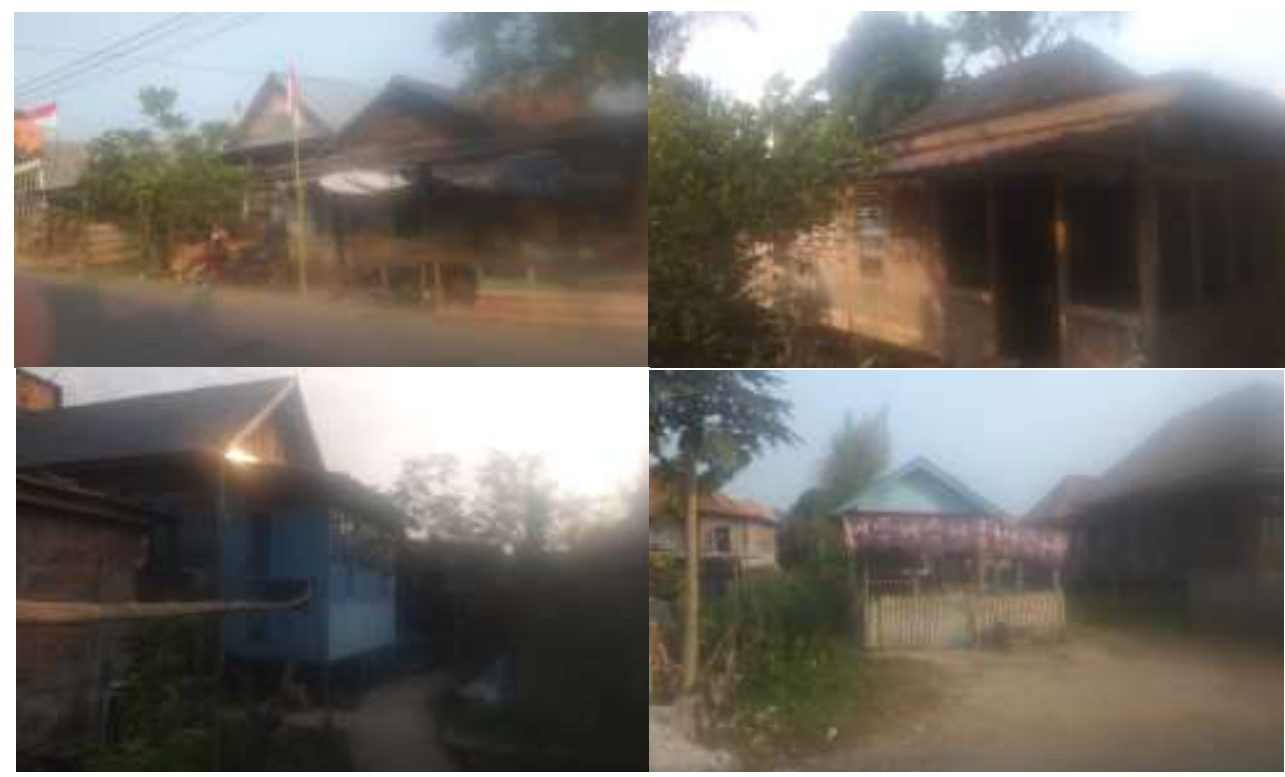

Gambar 1. Kondisi lingkungan target Mitra 
Untuk mencukupi kebutuhan sehari-hari, istri/ibu-ibu bekerja dengan mencari upahan menjahit atau sebagai asisten rumah tangga. Paling tinggi upah yang diterima Rp.13.000/hari. Namun tidak seluruh ibu-ibu mendapat pekerjaan, karena kebutuhan pekerjanya terbatas. Berikut adalah beberapa gambar aktivitas ibu-ibu di daerah lingkungan target mitra:

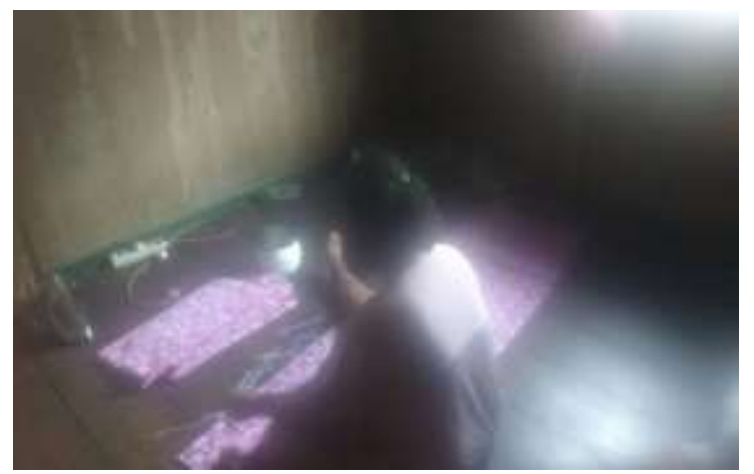

Gambar 2. Aktifitas Ibu Rumah tangga sekitar lingkungan target mitra

Tingginya kebutuhan hidup mempengaruhi kehidupan sosial. Rendahnya pendapatan keluarga menyebabkan timbul permasahan lain, yaitu banyak anak putus sekolah, tingginya tingkat kriminalitas seperti menjual atau mengkonsumi ganja/ sabu-sabu/ menghirup lem aibon, prostitusi dan pencurian (Hardianto, 2009) (Hardianto, 2009)

2. Permasalah dibidang usaha Pempek berbahan nasi

Usaha yang dipilih oleh tim pengabdian adalah memperkenalkan dan mempromosikan usaha pempek berbahan nasi. Pempek merupakan warisan ragam kuliner masyarakat Sumatera Selatan.

Upaya yang dilakukan adalah mempekenalkan dan mempromosikan kuliner khas masyarakat Palembang yang belum banyak dikenal oleh masyarakat Palembang dan luar Palembang. Bahan baku Pempek berbahan nasi terbuat dari nasi, tepung terigu, tepung beras, bawang putih, telor, santan, dan garam. Tahap pertama pembuatan Pempek berbahan nasi dengan menghaluskan nasi terlebih dahulu, kemudian setelah nasi halus campurkan bawang putih yang telah dihaluskan, tepung terigu, tepung beras, telor, santan, garam, dan air secukupnya, selanjutnya adonan diaduk hingga tercampur rata. Sebelum direbus pempek nasi dimasukan terlebih dahulu dalam plastik bening ukuran $7 \times 18 \mathrm{~cm}$ agar adonan pempek terbentuk. Proses perebusan dilakukan selama \pm 15 menit dan setelah pempek nasi masak kemudian tiriskan dan pempek nasi siap disajikan. Bahan baku pembuatan Pempek berbahan nasi sangat mudah dicari karena tidak memerlukan bahan baku yang sulit.

\subsection{Identifikasi Permasalahan}

Permasalahannya adalah biaya produksi yang agak tinggi seperti harga ikan menyebabkan harga jual pempek berangsur naik dan omset yang diterima tidak signifikan, maka Tim pengabdian melakukan observasi terhadap harga beras selaku pengganti ikan.

1. Dari hasil observasi dapat disimpulkan bahwa harga beras sekitar Rp 10.000/kg harga yang terjangkau ini bisa dijadikan pengganti ikan sarden/ikan sungai di pasaran yang harganya sekitar Rp20.000./kg sehingga harga jual pempek berbahan nasi lebih murah dan terjangkau masyarakat menengah kebawah.

2. Pempek berbahan nasi bisa digunakan sebagai makanan pokok sehingga masyarakat yang perekonomian menengah kebawah bisa mengkonsumsi pempek berbahan nasi tersebut tanpa menggunakan lauk tambahan lagi.

\subsection{Tujuan Kegiatan Pengabdian Pada Masyarakat}

Tujuan dari kegiatan pengabdian ini adalah memperkenalkan dan mempromosikan usaha pempek berbahan nasi ditempat target mitra sehingga menjadi makanan pengganti ikan agar dapat meningkatkan penghasilan warga sekitar. (Alimudin, A., \& Yoga, 2015).

\subsection{Manfaat Kegiatan}

Program pengabdian pada masyarakat ini diharapkan para peserta dapat mengetahui cara membuat pempek berbahan nasi dan bisa menjualnya sebagai penghasilan tambahan. 


\section{METODE PELAKSANAAN PENGABDIAN}

Kegiatan pengabdian kepada masyarakat terdiri dari beberapa kegiatan.

\section{Tahap-1 : Persiapan pelaksanaan PKM}

Kegiatan Pengabdian ini melibatkan dosen fakultas ekonomi dengan pembagian tugas masing masing ada yang mensurvey lokasi, penyebaran kuisoner ,menyiapkan berkas berkas yang diperlukan, serta pendekatan pada target mitra dan narasumber

\section{Tahap-2 : Observasi lokasi}

Pada saat proposal ini diajukan, tim pengabdian telah mendapatkan persetujuan untuk melaksanakan kegiatan pengabdian di lokasi mitra. Untuk memantapkan rencana tersebut, maka tim pengabdian akan berdiskusi dengan Ketua RT. 11 menetapkan jadwal yang fix, teknis kegiatan, tempat pelaksanaan, target peserta dan program pelatihan yang akan diberikan.

\section{Tahap-3 : Pelatihan}

Inti kegiatan pengabdian berada pada tahap ini. Tim pengabdian akan memberikan 4 macam pelatihan pada target mitra, yaitu :

\section{A. Pelatihan Pembuatan Pempek Nasi :}

\begin{tabular}{lll}
\hline Tujuan & $:$ & Memberikan pelatihan tentang caramembuat pempek nasi \\
Peran mitra & $:$ & Sebagai peserta pelatihan \\
Materi & $:$ & Teknik memilih bahan berkualitas baik, cara membuat pempek nasi dari \\
& proses membuat adonan sampai pembungkusan \\
Narasumber & $:$ & Reni Aziatul Febriani, SE., Msi \\
Teknik pelatihan & $:$ & Pemaparan materi dan Praktek langsung \\
Bahan praktek & $:$ & nasi, bumbu, air, wadah plastik dll, Fc. Bahan pelatihan \\
Lama pelatihan & $:$ & 4 jam (selama 1 hari) \\
Indikator & $:$ & Peserta dapat membuat pempek nasi \\
Keberhasilan &
\end{tabular}

\section{B. Memberikan Pelatihan Pencatatan Administrasi Produksi dan Penjualan Pempek Nasi (Pembukuan)}

\begin{tabular}{lll}
\hline Tujuan & $:$ & Memberikan Pelatihan Tentang Pembukuan Sederhana \\
Peran mitra & $:$ & Sebagai Peserta Pelatihan \\
Materi & $:$ & $\begin{array}{l}\text { Menghitung Harga Pokok Penjualan (Modal) dan Membuat Perhitungan } \\
\text { Narasumber }\end{array}$ \\
Neknik pelatihan & $:$ & Meilin Veronica SE.,M.M.,Ak.,CA \\
Bahan praktek & $:$ & Map Plastik, Pena, Note Book, Fc. Bahan Pelatihan \\
Lama pelatihan & $:$ & 4 Jam ( Selama 1 Hari ) \\
Indikator & $:$ & Peserta Dapat Membuat Pembukuan Sederhana \\
Keberhasilan &
\end{tabular}




\section{Pelatihan tentang Pengenalan Bentuk Packaging Shape (Bentuk Kemasan) :}

\begin{tabular}{ll}
\hline Tujuan & $\begin{array}{l}\text { : Memberikan Sosialisasi tentang Dampak Penggunaan Nama Produk (Brand } \\
\text { Image) dan Pemilihan Bentuk Kemasan (Packaging Shape) }\end{array}$ \\
Peran mitra & $:$ Sebagai Peserta \\
Materi & $:$ Pengetahuan Tentang Teknik Membuat Logo, Merek Dan Packaging Shape, HaKI \\
Narasumber & $:$ Rafika Sari., S.E.,M.Si \\
Teknik pelatihan & $:$ Pemaparan Materi dan Tanya Jawab Fc. Bahan \\
Bahan praktek & $:$ Sosialisasi \\
Lama pelatihan & $:$ 3 Jam (Selama 1 Hari) \\
Indikator & $:$ Peserta Memahami Pentingnya Nama Merek (Brand Image) dan Bentuk \\
Keberhasilan & Kemasan (Packaging Shape)
\end{tabular}

\section{Pelatihan Tentang Pengenalan Pemasaran Secara Online}

\begin{tabular}{ll}
\hline Tujuan & $\begin{array}{l}\text { : Memberikan Sosialisasi Tentang Melakukan Pemasaran dengan Media Social } \\
\text { dan E -Commerce (Aspek IPTEK dalam Segi Pemasaran) }\end{array}$ \\
Peran mitra & $:$ Sebagai Peserta \\
Materi & $:$ Pengetahuan tentang Cara Memasarkan Secara Online \\
Narasumber & $:$ Rafika Sari., S.E.,M.Si \\
Teknik pelatihan & $:$ Pemaparan Materi dan Tanya Jawab Fc. Bahan \\
Bahan praktek & $:$ Sosialisasi \\
Lama pelatihan & $:$ 3 Jam (Selama 1 Hari) \\
Indikator & $:$ Peserta Memahami Cara Memasarkan Produk Melalui Media Online \\
Keberhasilan &
\end{tabular}

\section{HASIL DAN PEMBAHASAN}

Luaran yang dihasilkan pada kegiatan pengabdian kepada masyarakat berdasarkan kegiatan adalah

\begin{tabular}{|c|l|c|}
\hline No & \multicolumn{1}{|c|}{ Kegiatan } & Luaran \\
\hline 1 & Pelatihan pembuatan pempek nasi & Produk dan sertifikat \\
\hline 2 & Pelatihan pencatatan transaksi (pembukuan) \\
\hline 3 & $\begin{array}{l}\text { Pelatihan tentang pengenalan bentuk packaging (bentuk } \\
\text { kemasan) yang menarik untuk meningkatkan imege baru dari } \\
\text { pempek nasi }\end{array}$ & Sertifikat \\
\hline 4 & $\begin{array}{l}\text { Pelatihan menggunakan alat blender plastic bungkus dan kukus } \\
\text { pempek nasi }\end{array}$ & Sertifikat \\
\hline 5 & $\begin{array}{l}\text { Pelatihan menggunakan media online, social media untuk } \\
\text { pemasaran }\end{array}$ & Sertifikat \\
\hline
\end{tabular}

Solusi dari permasalah mitra adalah dengan membangun kelompok usaha bagi ibu-ibu rumah tangga untuk berkreasi memproduksi pempek nasi yang memiliki standar produksi, kualitas yang baik dan bentuk kemasan yang menarik, sehingga dapat bersaing dengan produk makanan khas palembang lainnya. Adapun kegiatan yang direncanakan adalah memberikan beberapa pelatihan untuk meningkatkan soft dan hard skill target mitra (Seto, Andriyani \& Putra, 2017), yaitu :

1. Pelatihan pembuatan pempek nasi; 
2. Pelatihan pencatatan transaksi pengeluaran dan penerimaan dari pempek nasi (pembukuan).

3. Pelatihan tentang pengenalan bentuk Packaging (bentuk kemasan) yang menarik untuk $\mathrm{pe} \mathrm{m}$ pek $\mathrm{n}$ as i

4. Sosialisasi tentang pengurusan izin usaha.

5. Pelatihan membuat adonan pempek berbahan nasi.

6. Gambaran iptek yang akan diimplemetasikan ke mitra adalah menggunakan aplikasi grab, gojek, sosial media seperti instagram, facebook dan whatsapp.

\section{KESIMPULAN}

Berdasar hasil pelaksanaan kegiatan pengabdian kepada masyarakat ini dan uraian pembahasan di atas, dapat disimpulkan beberapa hal sebagai berikut :

1. Tindak Lanjut Hasil Evaluasi

Evaluasi pelaksanaan program menjadi dasar untuk melakukan perbaikan. Tim pengabdian dapat memberikan kembali pelatihan yang kurang dipahami oleh peserta, karena tujuan dari kegiatan pengabdian ini adalah membentuk kelompok usaha mandiri yang akan dikoordinir oleh Ketua RT.

2. Perluasan Market Penjualan

Ruang lingkup kegiatan pengabdian tidak membahas tentang market penjualan. Rencana penjualan kreasi pempek berbahan nasi akan dilakukan secara (1) Konvensional yaitu dititip kebeberapa toko (2) Online yaitu melalui aplikasi penjualan produk UMKM atau melalui media sosial yang lagi trend saat ini.

3. Inovasi Produk

Produk pempek berbahan nasi saat ini memiliki satu varian (rasa asin). Untuk inovasi produk dapat dilakukan percobaan dari bentuk dan kemasan.

\section{Saran}

Program pelatihan ini sangat bermanfaat dalam upaya meningkatkan wawasan dan pengetahuan para wirausahawan dalam memproduksi Pempek Nasi.

Beberapa saran yang dapat diterapkan, yakni :

1. Membuat kuesioner untuk mengukur tingkat keberhasil program pengabdian. Kuesioner disusun berdasarkan Indikator keberhasilan. Data yang terkumpul dianalisa dengan menggunakan metode kuantitaif. Hasil analisa menunjukkan indikator apa saja yang tercapai dan yang tidak tercapai

2. Menggunakan sosial media

3. Memilih tempat strategis

4. Menjalin hubungan baik dengan pelanggan

5. Mengembangkan jalur distribusi intensif

\section{UCAPAN TERIMA KASIH}

Tim Pengabdi Pada Masyarakat UIGM Menyampaikan Ucapan Terima Kasih yang Sebesar-besarnya atas Kerjasama dalam Pelaksanaan Kegiatan PPM tersebut, epada :

1. Fakultas Ekonomi UIGM

2. Lembaga Penelitan dan Pengabdian Masyarakat UIGM

3. Bapak M. Zaini selaku Ketua RT.11 RW.04 Kelurahan Karang Anyar Kecamatan Gandus Palembang Ketua

4. Para Mahasiswa Prodi Manajemen

\section{DAFTAR PUSTAKA}

Anita, Sumarni bayu. 2012. Kuliner dan Kinstruksi Identitas kelokalan studi kasus tentang pempek bagi "wong Kito" di kota Palembang. Tesis. Universtas Gajah mada.Perpustakaan Pusat UGM.

Alimudin, A., \& Yoga, H. 2015. Strategi Meningkatkan Loyalitas Pelanggan Pada Usaha Kecil Produk Makanan Ringan Di Surabaya. Sustainable Competitive Advantage (SCA), 5(1), 1-12.

Besra, E. 2012. Potensi Wisata Kuliner Dalam Mendukung Pariwisata Di Kota Padang. 
Hardianto, F. N. 2009. Analisis Faktor-Faktor Yang Mempengaruhi Tingkat Kriminalitas Di Indonesia Dari Pendekatan Ekonomi. Bina Ekonomi, 13(2), 28-41. Retrieved fromhttp://journal.unpar.ac.id/index.php/BinaEkonomi/article/view/713/697.

Heryati, A., \& Afriyani, F. 2017. Pelatihan Pembukuan Dan Manajemen Koperasi Bagi Pengurus Koperasi Smpn 26 Kota Palembang, 1(1), 41-45.

Hildayanti, S. K., \& Alie, J. 2017. Strategi Branding Usaha Kecil Industri Pempek Kelurahan 2 Ulu Dan 26 Ilir Palembang. Jurnal Abdimas Mandiri, 1(1), 26-30. Retrieved fromhttp://ejournal.uigm.ac.id/index.php/PGM/article/view/286.

Kimbal, R.W. 2015. Modal Sosial Dan Ekonomi Industri Kecil Sebuah Studi Kualitatif.Penerbit : Depublish, Yogyakarta.

Sanmorino, A. 2017. Pemanfaatan Teknologi Informasi Berupa Web Based Application Pada Sektor $\begin{array}{lllll}\text { Usaha Kecil Dan } & \text { 7-13. } & \text { Retrieved }\end{array}$ fromhttp://ejournal.uigm.ac.id/index.php/PGM/index. 